\title{
Serological and Molecular Characterization of Peanut chlorotic fan-spot virus, a New Species of the Genus Tospovirus
}

\author{
Fang-Hua Chu, Chia-Hung Chao, Ying-Cheh Peng, Shih-Shun Lin, Ching-Chung Chen, and Shyi-Dong Yeh
}

First, third, fourth, fifth, and sixth authors: Department of Plant Pathology, National Chung Hsing University, Taichung, Taiwan; and second author: Taichung District Agricultural Improvement Station, Changhua, Taiwan, R.O.C. Accepted for publication 10 May 2001.

\begin{abstract}
Chu, F.-H., Chao, C.-H., Peng, Y.-C., Lin, S.-S., Chen, C.-C., and Yeh, S.-D. 2001. Serological and molecular characterization of Peanut chlorotic fanspot virus, a new species of the genus Tospovirus. Phytopathology 91:856-863.

To clarify the serological relationship of Peanut chlorotic fan-spot virus (PCFV) with other tospoviruses, antisera were produced against the nucleocapsid $(\mathrm{N})$ proteins of this virus and tospoviruses from four serogroups including Tomato spotted wilt virus (TSWV), Impatiens necrotic spot virus (INSV), Groundnut ringspot virus (GRSV), and Watermelon silver mottle virus (WSMoV). In immunodiffusion tests, the antisera only reacted with their homologous antigens. Similar results were noticed in indirect enzyme-linked immunosorbent assay and immunoblot tests, with the exception that strong cross-reactions were observed in heterologous combinations between TSWV and GRSV. The results indicated that the N protein of PCFV is not serologically related to those of the tospoviruses

from the four serogroups. To further characterize the virus, viral $\mathrm{S}$ double-stranded RNA was extracted from PCFV-infected Chenopodium quinoa and used for cDNA cloning and sequencing. The full-length viral strand of the S RNA was determined to be 2,833 nucleotides, with an inverted repeat at the $5^{\prime}$ and $3^{\prime}$ ends and two open reading frames in an ambisense arrangement. The $3^{\prime}$-terminal sequence ( $5^{\prime}$-AUUGCUCU- $3^{\prime}$ ) of the viral S RNA is identical to those of other tospoviruses, indicating that PCFV belongs to the genus Tospovirus. The N and the NSs proteins of PCFV share low amino acid identities (22.3 to 67.5\% and 19.3 to $54.2 \%$ ) with those of reported tospoviruses, respectively. The phylogenetic dendrogram of the $\mathrm{N}$ gene of PCFV compared with those of other tospoviruses indicates that PCFV is distinct from other tospoviruses. In hybridization analyses, an $\mathrm{N}$ gene cDNA probe of PCFV did not react with viral RNAs of TSWV, GRSV, INSV, and WSMoV, and vice versa. Thus, based on these results, we conclude that PCFV is a new tospovirus species.
\end{abstract}

The genus Tospovirus in the family Bunyaviridae comprises plant viruses that have quasi-spherical, enveloped particles with diameters of 80 to $100 \mathrm{~nm}(4,24,35,49)$ and a tripartite singlestranded (ss) RNA genome $(16,18,48)$. The L RNA is of negative polarity (13), and the $\mathrm{M}$ and $\mathrm{S}$ RNAs have an ambisense coding strategy $(6,14,15,27,31-33)$. Tospovirus virions contain at least four structural proteins, denoted L (the putative RNA polymerase), G1/G2 (membrane glycoproteins), and $\mathrm{N}$ (nucleocapsid) that are encoded by L, M, and S RNAs, respectively $(28,29,36,47)$. Criteria for tospovirus classification have been proposed (20). Viruses within the genus Tospovirus must have similar virion morphology, genome organization, and a vector relationship with thrips. In addition to vector specificity and host range, sequence homology of $\mathrm{N}$ gene is one of the important criteria for designation to the species level (20).

Based on the serological relationships of $\mathrm{N}$ proteins, tospoviruses have been classified into 10 serogroups that represent possibly 13 species $(3,8,26,37)$. Among these, Tomato spotted wilt virus (TSWV), Groundnut ringspot virus (GRSV), Impatiens necrotic spot virus (INSV), and Watermelon silver mottle virus (WSMoV) are the typical representatives of originally proposed serogroups I, II, III, and IV, respectively $(1,10,30,51)$. Viruses in these four serogroups are the most prevalent tospoviruses.

In 1992, a tospovirus-like virus was isolated from peanut in central Taiwan and denoted Tospo-P and later named Peanut

Corresponding author: S. D. Yeh; E-mail address: sdyeh@nchu.edu.tw

The nucleotide sequence reported in this paper is GenBank Accession No. AF080526.

Publication no. P-2001-0627-01R

(C) 2001 The American Phytopathological Society chlorotic fan-spot virus (PCFV) (5). The virus is transmitted by Scirtothrips dorsalis Hood in a persistent manner (5). Symptoms in infected peanut include fan-shaped chlorotic spots with line patterns along the main veins of leaflets (5). Based on host range, thrips specificity, and the preliminary results of serological tests, PCFV was considered to potentially represent a new tospovirus species (52).

In this study, the taxonomic position of PCFV was investigated based on serological relationships of the $\mathrm{N}$ protein and nucleotide sequence comparison of the S RNA with those of other tospoviruses. Heterologous antigens and antisera were used to reciprocally analyze the serological relationships of the N protein of PCFV with those of TSWV, GRSV, INSV, and WSMoV by immunodiffusion, indirect enzyme-linked immunosorbent assay (ELISA), and immunoblotting. To further characterize the virus, the fulllength sequence of the PCFV S RNA was determined, and the phylogenetic relationships of the $\mathrm{N}$ gene of PCFV with those of other tospoviruses were analyzed. From the results of the serological comparison and molecular characterization, we conclude that PCFV is a new tospovirus species.

\section{MATERIALS AND METHODS}

Virus sources. Tospo-PD2, a typical isolate of PCFV, was collected from peanut leaves with fan-spot symptoms at Datsuen, Changhua County in central Taiwan (5). The other tospoviruses used in this study included an isolate of TSWV collected from tomato in New York State (denoted TSWV-NY, serogroup I, provided by R. Provvidenti, New York State Agricultural Experiment Station, Geneva), an isolate of GRSV collected from tomato in Brazil (denoted GRSV-B, serogroup II, provided by D. Gonsalves, New York State Experiment Agricultural Station) (39), an isolate 
of INSV collected from impatiens in the United States (denoted INSV-M, serogroup III, provided by J. Moyer, North Carolina State University, Raleigh) (30), and an isolate of WSMoV (serogroup IV) collected from watermelon in Taiwan (54). The viruses were maintained in the systemic host Nicotiana benthamiana Domin. and the local lesion host Chenopodium quinoa Willd. by sap transmission.

Purification of $\mathbf{N}$ proteins and production of antisera. Leaf tissues of the local lesion host $C$. quinoa, collected 4 to 5 days after inoculation with TSWV, GRSV, INSV, WSMoV, or PCFV, were used for the purification of viral nucleocapsids according to the method of Yeh et al. (52), with some modifications. To minimize the loss of the $\mathrm{N}$ proteins and remove host plant components, Triton X-100 was added to $1 \%$ of the supernatant after the initial low speed centrifugation. This treatment resulted in clearer extracts, making the nucleocapsid zone easier to collect after centrifugation in $35 \%(\mathrm{wt} / \mathrm{vol})$ cesium sulfate. The $\mathrm{N}$ proteins of the five tospoviruses were dissociated from the purified nucleocaspids and subjected to preparative polyacrylamide slab-gel electrophoresis as described previously (53). Antisera to the purified N proteins of PCFV, TSWV, GRSV, INSV, and WSMoV were produced in New Zealand white rabbits as described by Yeh and Gonsalves (53).

Serological analyses. Sodium dodecyl sulfate (SDS)-immunodiffusion tests were conducted as described by Purcifull and Batchelor (40). Agar plates contained $0.8 \%$ agarose, $1.0 \%$ sodium azide, and $0.5 \%$ SDS. Crude antigens were prepared from freshly harvested leaves of $N$. benthamiana, infected with individual tospoviruses, by grinding $1 \mathrm{~g}$ of tissue in $1 \mathrm{ml}$ of distilled water and adding $1 \mathrm{ml}$ of $3 \%$ SDS. Antisera to the purified $\mathrm{N}$ proteins of PCFV, TSWV, GRSV, INSV, and WSMoV were tested with homologous and heterologous crude antigens. Undiluted antisera were placed in appropriate wells $(0.5-\mathrm{cm}$ diameter, separated by a distance of $0.5 \mathrm{~cm}$ ), and the plates were incubated in a moist chamber at room temperature for 18 to $36 \mathrm{~h}$. In order to avoid the formation of precipitin lines too close to the wells, each antiserum was loaded $2 \mathrm{~h}$ prior to the loading of the antigens.

The indirect ELISA procedure was similar to that described by Wang and Gonsalves (50). The plates were coated with crude extracts diluted 50 -fold in coating buffer $(0.05 \mathrm{M}$ sodium carbonate, $\mathrm{pH} 9.6$, containing $0.01 \%$ sodium azide). Antisera against the five tospoviruses were used at a dilution of 1:2,000 in conjugate buffer (phosphate-buffered saline containing $0.05 \%$ Tween 20, $2 \%$ polyvinylpyrrolidone- 40 and $0.2 \%$ ovalbumin). The secondary antibody, goat anti-rabbit immunoglobulin G (IgG) alkaline phosphatase conjugate (Kirkegaard \& Perry Laboratories, Gaithersburg, MD), was diluted 1:2,000 in conjugate buffer. Substrate solution was prepared by dissolving alkaline phosphatase tablets (Sigma Chemical, St. Louis) in substrate buffer $(97 \mathrm{ml}$ of diethanolamine and $0.2 \mathrm{~g}$ of $\mathrm{NaN}_{3}$ per liter, $\mathrm{pH}$ 9.8) to a final concentration of $1 \mathrm{mg} / \mathrm{ml}$. Reactions were recorded by a Rainbow microplate reader (SLT, Groding, Austria) 20 to 30 min after the addition of the substrate.

Immunoblotting was conducted according to the method described by Gooderham (21). Crude antigens (10 $\mu \mathrm{l})$ extracted from leaf tissues of $N$. benthamiana infected with individual tospoviruses (in $3 \mathrm{ml}$ of dissociation buffer per gram of tissue) were loaded onto a $12 \%$ polyacrylamide gel, fractionated, and transferred to nitrocellulose membranes. Subsequently, each membrane was incubated with the antisera against the $\mathrm{N}$ proteins $(1: 3,000$ dilution), followed by the alkaline phosphatase-conjugated antirabbit IgG (1:5,000 dilution) and the development substrate (nitroblue tetrazolium/5-bromo-4-chloro-3-indoyl phosphate paratoluidine salt in $100 \mathrm{mM} \mathrm{NaCl}, 5 \mathrm{mM} \mathrm{MgCl}$, and $100 \mathrm{mM}$ Tris- $\mathrm{HCl}$, $\mathrm{pH}$ 9.5). Extracts from leaves of uninfected plants were used as controls.

Construction of a cDNA library and hybridization selection. Viral double-stranded (ds) RNAs were isolated from infected $C$. quinoa as described by Yeh and Chang (51). The S dsRNA of PCFV was resolved on an agarose gel, eluted, and used for the construction of a cDNA library. The $\mathrm{S}$ dsRNA was denatured by methylmercuric hydroxide ( $\mathrm{MeHg}$ ) according to Bailey and Davidson (2). The cDNA library was constructed according to the protocols of ZAP-cDNA synthesis and cloning (Stratagene, La Jolla, CA). The ds cDNA was blunt-ended with T4 DNA polymerase ( 9 units per $\mu \mathrm{l})$ and ligated with EcoRI adapter. The dsDNA was inserted into lambda ZAP-II EcoRI/CIAP vector (Stratagene) and packaged by capsid proteins (ZAP-cDNA Gigapack II Gold Cloning Kit; Stratagene). The $\left[{ }^{32} \mathrm{P}\right]$-labeled cDNA probe used for plaque screening was synthesized from $\mathrm{MeHg}$-denatured $\mathrm{S}$ dsRNA by random priming according to Maniatis et al. (34).

Polymerase chain reaction amplification and cloning for intergenic and terminal regions. Two cDNA clones, $\mathrm{pS1} 2$ and $\mathrm{pS} 3$, covered most of the S RNA, but lacked the intergenic region and the $5^{\prime}$ and $3^{\prime}$ ends. Thus, reverse transcription-polymerase chain reaction (RT-PCR) was performed with primer S6t7 (5'-GTCGACTATTGTGACAATAA-3') and primer S12-166 (5'-GGCAACTTGAATCACCTCATGGG-3'), both designed from the known regions, to amplify the intergenic region for cloning. The PCFV $5^{\prime}$ - and $3^{\prime}$-terminal regions were cloned using the $5^{\prime}$-rapid amplification of cDNA ends (RACE) amplification system (Gibco BRL, Gaithersburg, MD). First cDNA was synthesized from $\mathrm{S}$ dsRNA with primer S12-155 (5'-CAAGTTGCCTCCAGTCACC$\left.3^{\prime}\right)$ or primer S6t3 (5'-GTGACATCAGGTGTTACCCT-3'), both designed from known regions, by Superscript II reverse transcriptase (Gibco BRL). After removal of template RNA by RNase $\mathrm{H}$ digestion, the first strand cDNA was tailed with dCTP and terminal deoxynucleotidyl transferase. The dC-tailed cDNA was amplified with Taq polymerase with an anchor primer (5'-GGCCACGCGTCGACTAGTACGGGGGGGGGGGGGGGG) and downstream primer PDNSS1 (5'-GGATTGCATGAATACTGTGATCG$3^{\prime}$ ) designed from the known sequence of the $5^{\prime}$-terminal region or PDNP1 (5'-GAAACACTACTCTCTCTTCCTATGG-3') designed from the known sequence of the $3^{\prime}$-terminal region. PCR products were cloned in the pCR2.1 vector (Invitrogen, San Diego, CA) for sequencing.

DNA sequencing and analysis. DNA sequencing was performed by the dideoxynucleotide chain termination method (43), using ssDNA templates generated by VCSM13 (Stratagene) or dsDNA templates (23) prepared from the clones obtained from cDNA library and PCR products. Nucleotide sequence determination was performed with a sequencing kit (Sequenase version 2.0 DNA, United States Biochemical, Cleveland). Sequence data were assembled and amino acid sequences were predicted using the PC/GENE 6.85 software (IntelliGenetics, University of Geneva, Switzerland). Sequence comparisons were conducted with the GAP program of the Genetics Computer Group (GCG) package (version 9.0, Genetics Computer Group, Madison, WI). The PILEUP program from the GCG package was used to create multiple sequence alignments. Distance matrices for protein sequences were calculated from alignments based on the Dayhoff for protein PAM matrix (9), using the PROTDIST program of PHYLIP package version 3.5c (Department of Genetics, University of Washington, Seattle). Phylogenetic relationships were estimated from these distances using the Neighbor-Joining routines. The repeatability of the branch orders obtained was estimated using the SEQBOOT program for bootstrap resampling (300 bootstrap reiterations) (17). Bootstrap consensus trees were built using the CONSENSE program. The NEIGHBOR unrooted tree was drawn using the DRAWTREE program. Sequences for alignments were obtained from the EMBL, GenBank, and DDBJ databases under the following accession numbers: TSWV, D13926 (15); INSV, D00914 (12); Peanut bud necrosis virus (PBNV), U27809 (45); Tomato chlorotic spot virus (TCSV), S54325 (10); GRSV, S54327 (39); WSMoV, X78556 (55); Watermelon bud necrosis 
virus (WBNV), U27809 (25); Iris yellow spot virus (IYSV), AF001387 (7); Peanut yellow spot virus (PYSV), AF013994 (44); Physalis severe mottle virus (PSMV), AF067151 (8); Chrysanthemum stem necrosis virus (CSNV), AF067068 (3); Zucchini lethal chlorosis virus (ZLCV), AF067069 (3); and Melon yellow spot virus (MYSV), DDBJ Accession No. AB024332 (26).

Dot blot hybridization. The relationship of PCFV to other tospoviruses was further analyzed by nucleic acid hybridization. The DNA clones used covered the 3 '-noncoding region, the complete $\mathrm{N}$ open reading frame (ORF), and part of the intergenic region. The PCFV $\mathrm{N}$ gene construct was obtained by RT-PCR with downstream primer 5'-CGGGATCCAGAGCAATCTTGGC$3^{\prime}$ and upstream primer 5'-GCGAGCTCGTAGCTTAAATGCAGACACAGG-3'. The N gene clones of TSWV, GRSV, and INSV were obtained by RT-PCR with a common forward primer $\left(5^{\prime}\right.$ CGGGATCCAGAGCAATTGTGTCA-3') and a species-specific reverse primer (5'-GCGAGCTCTTAACACACTAAGCAAGCAC$3^{\prime}$ for TSWV, 5'-GCGAGCTCCTGACTTTATCACACTTAACACGC-3' for GRSV, and 5'-GCGAGCTCTTATTTCAAATAATTTATAAAAGCAC-3' for INSV). The $\mathrm{N}$ gene clone of WSMoV was obtained from available cDNA clones (51). Total RNAs were extracted from uninfected plants of $N$. benthamiana as well as from plants individually infected with TSWV, GRSV, INSV, WSMoV, or PCFV, using the protocol of the ULTRASPEC RNA isolation system (Biotecx, Houston, TX). Digoxigenin-labeled DNA probes, corresponding to the $\mathrm{N}$ genes of each of the five tospoviruses, were synthesized according to manufacturer's procedures (Boehringer Mannheim, Germany). The dot blot hybridization was completed according to the protocol of a detection starter kit (Boehringer Mannheim).

\section{RESULTS}

Purification of the $\mathbf{N}$ proteins of tospoviruses. When purified nucleocapsids of TSWV, GRSV, INSV, WSMoV, and PCFV were dissociated and analyzed by SDS-polyacrylamide gel electrophoresis, the sizes of the $\mathrm{N}$ proteins of each virus were estimated to be $29,29,28,32$, and $31 \mathrm{kDa}$, respectively (Fig. 1). The yields of the $\mathrm{N}$ proteins of PCFV and the other four tospoviruses were

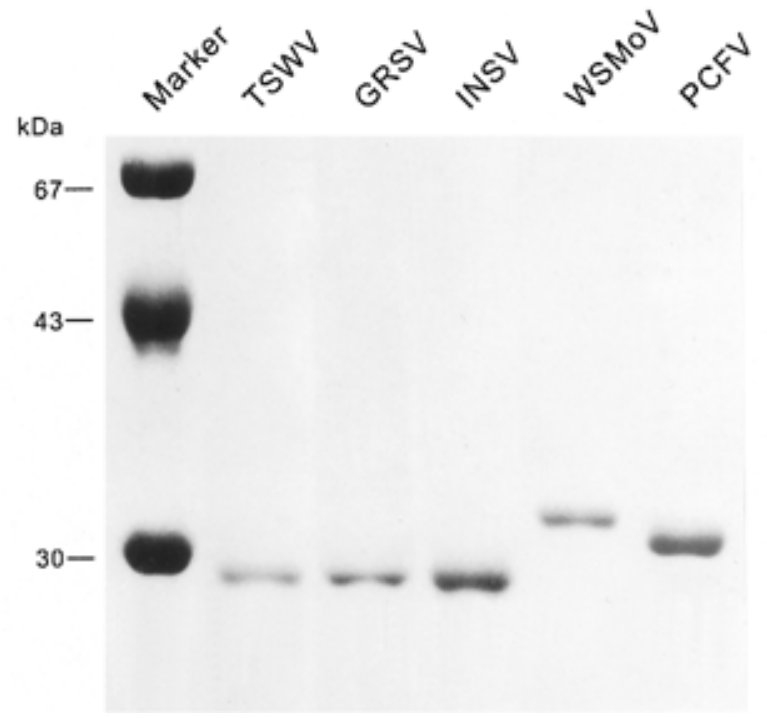

Fig. 1. Purified nucleocapsid $(\mathrm{N})$ proteins of tospoviruses were analyzed by sodium dodecyl sulfate-polyacrylamide gel electrophoresis in a $12 \%$ gel after isopycnic centrifugation. Lane $\mathrm{M}$, protein markers (low molecular weight calibration kit, Pharmacia). The purified N proteins of Tomato spotted wilt virus (TSWV), Groundnut ringspot virus (GRSV), Impatiens necrotic spot virus (INSV), Watemelon silver mottle virus (WSMoV), and Peanut chlorotic fan-spot virus (PCFV) are indicated. spectrophotometrically estimated $\left(A_{280}\right.$ of 1.0 unit was taken as $1 \mathrm{mg} / \mathrm{ml}$, not corrected for light scattering) to be 1 to $5 \mathrm{mg}$ per $100 \mathrm{~g}$ of infected tissue of C. quinoa.

Serological comparison of PCFV N protein to other tospoviruses. In SDS-immunodiffusion tests, the antiserum against the PCFV $\mathrm{N}$ protein only reacted with the crude antigen extracted from leaf tissue of PCFV-infected $N$. benthamiana plants. Similarly, the antisera to the $\mathrm{N}$ proteins of TSWV, GRSV, INSV, and WSMoV reacted only with their homologous crude antigens. No cross-reactions with the heterologous crude antigens were observed (Fig. 2A).

The results of indirect ELISA, using the antisera to the respective $\mathrm{N}$ proteins of TSWV, GRSV, INSV, WSMoV, and PCFV with the homologous and heterologous crude viral antigens extracted from infected plants of $N$. benthamiana, are shown in Figure 2B. Crude antigen of INSV, WSMoV, and PCFV reacted only with the homologous antiserum. The antiserum to the TSWV $\mathrm{N}$ protein reacted positively with crude antigens of TSWV and GRSV. Cross reaction with TSWV also was observed when the antiserum to GRSV N protein was used. However, in both cases, the reactions were stronger in the homologous combination than in the heterologous combination.

Results of the immunoblot tests (Fig. 2C) were similar to those obtained in ELISA experiments. The antiserum to the PCFV N protein reacted only with the homologous antigen. The antiserum to the TSWV N protein reacted with the homologous antigen and the $\mathrm{N}$ protein of GRSV, but did not react with the $\mathrm{N}$ proteins of INSV, WSMoV, and PCFV. Likewise, the antiserum to the GRSV $\mathrm{N}$ protein reacted with the homologous antigen and cross-reacted with the N protein of TSWV.

Complete nucleotide sequence of PCFV S RNA. Seven cDNA clones were selected by hybridization of the cDNA library, with cDNA probes derived from PCFV S dsRNA. These clones covered the complete nonstructural protein of S RNA (NSs) gene and most of the $\mathrm{N}$ gene of S RNA, except for the 5'- and 3 '-terminal regions and part of the intergenic region of $\mathrm{S}$ RNA. The cDNA clone of $0.9 \mathrm{kbp}$, corresponding to the complete intergenic region and the C-terminal region of the $\mathrm{N}$ gene, was obtained from RTPCR products amplified with primers S6t7 and S12-166 designed from the newly established sequence data. The nucleotide sequences of the $5^{\prime}$ - and $3^{\prime}$-terminal regions were determined by the $5^{\prime}$-RACE system, from a cDNA clone of $0.55 \mathrm{kbp}$ for the $5^{\prime}$ region and a cDNA clone of $0.45 \mathrm{kbp}$ for the $3^{\prime}$ region, respectively. Nucleotide sequences following the poly (G) tail in the $5^{\prime}$-endamplified and the $3^{\prime}$-end-amplified clones were complementary and, thus, were assumed to represent the $5^{\prime}$ and $3^{\prime}$ termini of the viral RNA.

The complete nucleotide sequence of the S RNA was assembled from the clones selected from the cDNA library and the RT-PCR clones. The S RNA of PCFV was 2,833 nucleotides (nts), which was $83,159,701,224,137,272$, and 424 nts shorter than those reported for TSWV (15), INSV (12), WSMoV (55), PBNV (45), PYSV (44), IYSV (7), and PSMV (8), respectively. The S RNA contained two ORFs, and one A-U rich intergenic region, as found in S RNAs of other tospoviruses. The two ORFs were presented in an ambisense arrangement and encoded the NSs protein in the viral strand and the $\mathrm{N}$ protein in the complementary strand.

Comparison of the $N$ and NSs genes with those of other tospoviruses. The N ORF was $810 \mathrm{nts}$, encoding a predicted protein of 270 amino acids with a calculated molecular mass of $31.1 \mathrm{kDa}$. The ORF started at nucleotide 2753 with an AUG start codon and terminated at nucleotide 1943 with an UAA stop codon. The predicted amino acid sequence of the PCFV $\mathrm{N}$ gene shared low amino acid identities of 22.3 to $28.1 \%$ with those of TSWV, GRSV, TCSV, INSV, WSMoV, PBNV, WBNV, IYSV, PSMV, CSNV, ZLCV, and MYSV, whereas it had a relatively higher amino acid identity $(67.5 \%)$ with that of PYSV (Table 1). These amino acid identities for the $\mathrm{N}$ gene of PCFV are far below the 
90\% threshold for classifying distinct tospovirus species (20), indicating that PCFV is a new tospovirus member.

Among the tospoviruses compared in Table 1, the $\mathrm{N}$ genes of TSWV, GRSV, TCSV, CSNV, and ZLCV had amino acid identities of 72.5 to $81.0 \%$, indicating that these viruses are relatively closely related. Similarly, the N genes of WSMoV, PBNV, and WBNV had high amino acid identities (84.7 to $86.2 \%$ ), reflecting the fact that these three viruses have strong serological cross-reactions and are classified in the same serogroup $(1,25$, 41,54).

The phylogenetic relationships of PCFV and other tospoviruses based on the $\mathrm{N}$ protein amino acid sequence are shown in Figure 3 . The dendrogram revealed that the tospoviruses originating in Asia, such as MYSV, PSMV, PBNV, WSMoV, and WBNV, were grouped in two related clusters, with IYSV distantly related to the two clusters. PBNV, WSMoV, and WBNV were grouped in the same cluster and had short genetic distances, whereas MYSV and PSMV were placed in the other cluster and had no genetic distance. Thus, our results indicated that PSMV isolated from Physalis minima in Taiwan (8) and MYSV isolated from melon in Japan (26) may be the same species because their $\mathrm{N}$ protein amino acid sequences are $99.6 \%$ identical (Table 1; Fig. 3) On the contrary, those tospoviruses prevalent in North and South America, such as TSWV, TCSV, GRSV, ZLCV, and CSNV, were grouped in another cluster, with INSV distantly related to this cluster. PCFV was most closely related to PYSV, although they were distinct from each other. PCFV and PYSV are clearly highly divergent from all other tospoviruses compared.

The predicted NSs ORF was 1,416 nts in length, encoding a predicted protein of 472 amino acids and a molecular mass of $51.5 \mathrm{kDa}$. The coding sequence initiated at nucleotide 68 with an AUG start codon and terminated at nucleotide 1486 with an UAG stop codon. The predicted amino acid sequence of the NSs gene of PCFV was 27.3, 19.3, 20.3, 23.2, 23.0, 54.2, 30.0, and $21.9 \%$ identical to those of TSWV (15), GRSV (38), INSV (12), WSMoV (55), PBNV (45), PYSV (44), PSMV (8), and IYSV (7), respectively (Table 2). These results showed that the PCFV NSs gene has a very low degree of identity with those of other tospoviruses.

Characteristics of terminal sequences and the intergenic region. The $5^{\prime}$-noncoding region of the viral sense PCFV S RNA was 67 nts and 40.3 to $66.7 \%$ identical to those of TSWV, GRSV, WSMoV, PBNV, PYSV, IYSV, and PSMV (Table 2). The 3'noncoding region of the viral sense of PCFV S RNA was 79 nts and 43.0 to $75.0 \%$ identical to those of TSWV, GRSV, TCSV, INSV, WSMoV, PBNV, PYSV, IYSV, WBNV, PSMV, CSNV, and ZLCV (Table 2). The 5'- and 3'-terminal regions of S RNA of PCFV contained an inverted complementary sequence, in which the first $16 \mathrm{nts}$ were complementary and able to form a stable panhandle structure, as previously reported for other tospoviruses $(15,55)$. The consensus sequence of 8 nts $\left(5^{\prime}\right.$-AUUGCUCU-3') found in the 3'-terminal sequences of the viral S RNAs of TSWV, GRSV, TCSV, INSV, WSMoV, PBNV, WBNV, PYSV, IYSV,
A

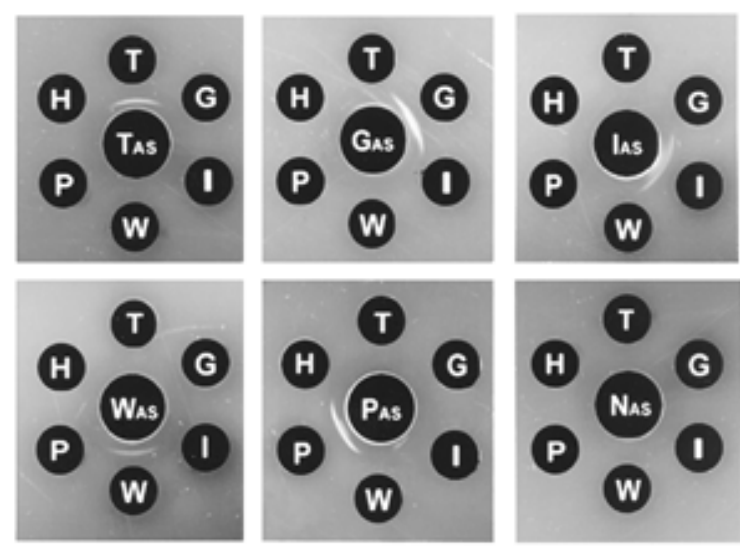

B

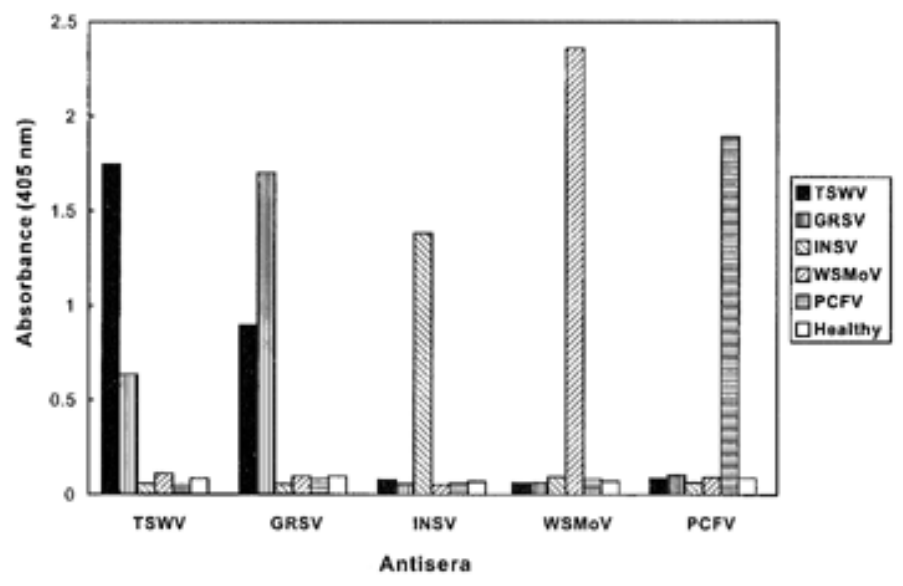

C

TSWV

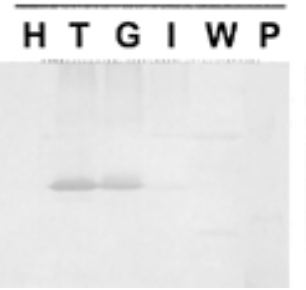

GRSV

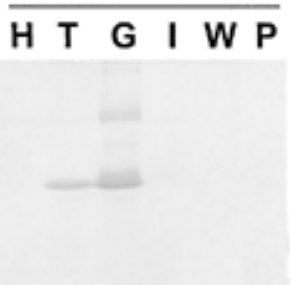

INSV

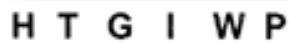

WSMoV

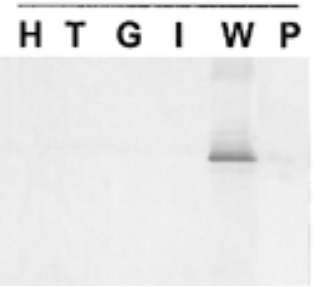

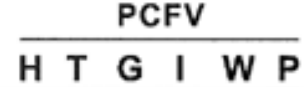

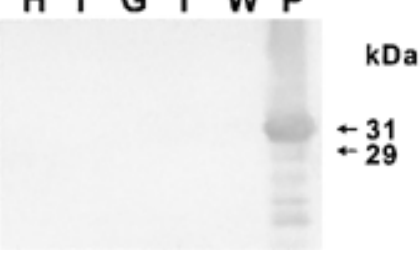

Fig. 2. Serological relationships among the nucleocapsid (N) proteins of Tomato spotted wilt virus (TSWV), Groundnut ringspot virus (GRSV), Impatiens necrotic spot virus (INSV), Watemelon silver mottle virus (WSMoV), and Peanut chlorotic fan-spot virus (PCFV) as determined by A, sodium dodecyl sulfateimmunodiffusion tests; B, indirect enzyme-linked immunosorbent assay (ELISA); and $\mathbf{C}$, immunoblotting, using polyclonal antibodies against purified $\mathrm{N}$ proteins. In immunodiffusion tests, undiluted antisera of $80 \mu \mathrm{l}$ were added to the central wells (1-cm diameter). TAS, GAS, IAS, WAS, and PAS represent the antisera to the N proteins of TSWV, GRSV, INSV, WSMoV, and PCFV, respectively. NAS represents normal serum. Crude antigens in 40- $\mu$ crude extracts of leaf tissues of virus-infected plants of Nicotiana benthamiana were added to the surrounding wells (0.5-cm diameter). T, G, I, W, and P represent the crude antigens from the plants infected with TSWV, GRSV, INSV, WSMoV, and PCFV, respectively. H, crude extract of an uninfected plant. In indirect ELISA, crude antigens (1/50 dilution) were extracted from healthy plants of $N$. benthamiana and plants individually infected with TSWV, GRSV, INSV, WSMoV, or PCFV. The rabbit antisera to the N proteins of TSWV, GRSV, INSV, WSMoV, and PCFV are indicated in the order from left to right. In immunoblot analysis, the specific antisera used are indicated above each set. Total proteins from virus-infected plants of $N$. benthamiana were used for analysis. $\mathrm{H}$, uninfected control. T, G, I, W, and P represent total proteins extracted from plants infected with TSWV, GRSV, INSV, WSMoV, and PCFV, respectively. 
PSMV, CSNV, ZLCV, and MYSV was also present in the $3^{\prime}$ terminal sequence of the viral S RNA of PCFV. The $5^{\prime}$ ends of the viral S RNA of these tospoviruses (except TCSV, INSV, WBNV, CSNV, ZLCV, and MYSV, for which the $5^{\prime}$ ends have not been elucidated) also shared a consensus sequence of $8 \mathrm{nts}\left(5^{\prime}\right.$ AGAGCAAU-3').

The intergenic region of PCFV S RNA was 455 nts. It was 54 to 806 nts shorter than those of TSWV, GRSV, INSV, WSMoV, PBNV, PYSV, IYSV, and PSMV, and was 44.7 to $52.8 \%$ identical with these tospoviruses (Table 2). The results of the analysis by the FOLDRNA program of GCG indicated that the A-U rich region has a potential to form hairpin structures similar to those reported for TSWV, INSV, WSMoV, and PBNV.

Hybridization analysis of the $\mathbf{N}$ genes of five tospoviruses. When tested by dot blot analyses, total RNA extracted from $N$. benthamiana plants infected with INSV, WSMoV, and PCFV reacted only with the DNA probe derived from the corresponding $\mathrm{N}$ gene. DNA probes derived from the $\mathrm{N}$ genes of TSWV and GRSV hybridized with RNAs prepared from leaves infected with either virus, with stronger signals detected for the homologous combination than the heterologous combination. No hybridization was observed with extracts from uninfected plants.

\section{DISCUSSION}

PCFV is thrips transmitted and its host range has been established (5). In this study, we have shown that the $\mathrm{N}$ protein of PCFV is serologically distinct from those of TSWV, GRSV, INSV, and WSMoV. In addition, our results also show that the deduced $\mathrm{N}$ protein amino acid sequence of PCFV is not highly similar to those of the known tospoviruses. The highest identity was with the N protein of PYSV (67.5\%), which is far below the $90 \%$ threshold for separation individual tospoviruses (20). Thus, we conclude that PCFV should be considered a new species of the genus Tospovirus.

Viruses from the genus Tospovirus of the family Bunyaviridae are unique in their ability to infect plants. Tospoviruses, such as TSWV and INSV, were originally prevalent in temperate regions (37). However, the devastation caused by new tospoviruses, for example, WSMoV in Taiwan (54); PBNV, WBNV, and PYSV in India $(41,42,44,45)$; GRSV, TSCV, CSNV, and ZLCV in Brazil (3); and IYSV in Israel and Brazil (3), together with the occurrence of PCFV in Taiwan (5), closely demonstrates that tospoviruses are also prevalent in tropical and subtropical regions. Apparently, the tropical and subtropical areas, where thrips species are abundant, represent another major center of diversity for this unique plant virus genus. It is likely that more new tospoviruses will be discovered in tropical and subtropical areas, because more emphasis is placed on their identification.

In view of the worldwide distribution and emergence of tospoviruses and their ability to infect a large number of economically important plant species, a simple, fast, and accurate method for determining relationships among tospoviruses is important not only for taxonomic interest but also for developing resistant varieties. Polyclonal antibodies are suitable for these purposes and, therefore, are commonly used for serological analyses. However, because tospovirus virions are enveloped, purification of the virus particles is difficult compared with other viruses. Traditionally, tospoviruses were purified from leaf tissue of systemically infected hosts such as Nicotiana spp., but because of the erratic appearance of symptoms and the wilting response, such hosts may not be suitable for purification. In this study, the local lesion host C. quinoa was used for purification of tospovirus $\mathrm{N}$ protein. Numerous coalescent lesions appeared almost simultaneously, and leaf tissues contained high concentrations of virus. The Triton X100 treatment was helpful for disrupting the envelopes to release nucleocapsids and for eliminating the interference by host material. Thus, the use of $C$. quinoa and Triton X-100 allowed for efficient recovery of purified tospovirus $\mathrm{N}$ proteins. The five antisera raised against the purified $\mathrm{N}$ proteins were highly specific in immunodiffusion, ELISA, and immunoblotting tests.

TSWV, GRSV, INSV, and WSMoV represent tospovirus serogroups I, II, III, and IV, respectively, in the genus Tospovirus $(1,11,30)$. The results of immunodiffusion, indirect ELISA, and immunoblotting tests indicate that the $\mathrm{N}$ protein of PCFV is serologically distinct from those of TSWV, GRSV, INSV, and WSMoV. Thus, it is concluded that PCFV constitutes a new serotype distinct from these serogroups.

In immunodiffusion tests, the antisera to the $\mathrm{N}$ proteins of TSWV and GRSV reacted only with their homologous crude antigens, whereas in immunoblotting and ELISA tests cross-reactions with the heterologous antigens occurred. Thus, the $\mathrm{N}$ proteins of TSWV and GRSV probably share common epitopes, but these epitopes are limited in number or do not take part in the formation of precipitate lines in immunodiffusion tests. However, when the more sensitive immunoblotting and ELISA tests were performed, strong cross-reactions between the antisera and the $\mathrm{N}$ proteins of TSWV and GRSV were obvious. Our results are similar to previous observations $(1,10,11)$ that the $\mathrm{N}$ proteins of these two serogroups share common epitopes.

TABLE 1. Percent nucleotide identities (above diagonal) and derived amino acid identities (below diagonal) for the $\mathrm{N}$ genes of various tospoviruses ${ }^{\mathrm{a}}$

\begin{tabular}{|c|c|c|c|c|c|c|c|c|c|c|c|c|c|c|}
\hline Virus & TSWV & GRSV & TCSV & CSNV & ZLCV & INSV & WSMoV & PBNV & WBNV & PSMV & MYSV & IYSV & PYSV & PCFV \\
\hline TSWV & & 76.7 & 75.8 & 74.0 & 72.7 & 57.0 & 44.4 & 46.2 & 43.3 & 46.2 & 46.1 & 47.1 & 41.9 & 43.6 \\
\hline GRSV & 78.3 & & 81.0 & 72.1 & 74.3 & 59.3 & 47.6 & 47.5 & 47.0 & 46.3 & 45.1 & 48.4 & 43.7 & 45.2 \\
\hline TCSV & 76.7 & 81.0 & $\ldots$ & 72.6 & 73.1 & 59.2 & 45.7 & 45.9 & 44.7 & 44.4 & 43.2 & 46.1 & 41.7 & 43.0 \\
\hline ZLCV & 72.9 & 76.0 & 72.5 & 79.6 & $\ldots$ & 59.3 & 47.5 & 46.5 & 47.3 & 47.0 & 44.4 & 47.5 & 41.7 & 45.5 \\
\hline INSV & 55.3 & 54.3 & 55.7 & 55.9 & 53.5 & $\cdots$ & 44.8 & 41.9 & 44.6 & 44.2 & 43.7 & 44.3 & 42.6 & 46.5 \\
\hline WSMoV & 33.7 & 34.3 & 31.5 & 33.3 & 32.4 & 32.2 & $\ldots$ & 80.9 & 79.3 & 62.9 & 62.5 & 53.9 & 43.5 & 44.5 \\
\hline PBNV & 32.8 & 34.0 & 33.6 & 33.7 & 32.4 & 31.4 & 86.2 & & 81.3 & 63.4 & 63.4 & 52.5 & 39.4 & 43.6 \\
\hline MYSV & 30.8 & 30.8 & 30.4 & 33.6 & 32.0 & 28.9 & 58.5 & 60.1 & 59.6 & 99.6 & $\ldots$ & 59.2 & 41.5 & 42.6 \\
\hline IYSV & 37.3 & 34.3 & 35.6 & 34.5 & 33.3 & 31.6 & 44.2 & 44.6 & 42.8 & 50.2 & 50.2 & & 42.0 & 41.1 \\
\hline PYSV & 24.1 & 24.5 & 26.8 & 25.2 & 23.6 & 25.5 & 23.4 & 22.5 & 25.5 & 25.3 & 25.3 & 27.4 & $\ldots$ & 68.6 \\
\hline PCFV & 24.4 & 25.3 & 26.7 & 26.9 & 26.4 & 24.5 & 28.1 & 26.1 & 26.7 & 22.3 & 22.3 & 23.7 & 67.5 & $\ldots$ \\
\hline
\end{tabular}

a Sequence comparisons were conducted with the GAP program of the Genetics Computer Group (GCG) package (version 9.0; Genetics Computer Group, Madison, WI). The GenBank codes of the nucleotide sequences are: TSWV, Tomato spotted wilt virus (D13926); GRSV, Groundnut ringspot virus (L12048); TCSV, Tomato chlorotic spot virus (S54325); CSNV, Chrysanthemum stem necrosis virus (AF067068); ZLCV, Zucchini lethal chlorosis virus (AF067069); INSV, Impatiens necrotic spot virus (X66972); WSMoV, Watemelon silver mottle virus (U78734); PBNV, Peanut bud necrosis virus (U27809); WBNV, Watermelon bud necrosis virus (U27809); PSMV, Physalis severe mottle virus (AF067151); MYSV, Melon yellow spot virus (DDBJ accession no. AB024332); IYSV, Iris yellow spot virus (AF001387); PYSV, Peanut yellow spot virus (AF013994); and PCFV, Peanut chlorotic fan-spot virus (AF080526). The sequence identities of the viruses that potentially have serological relationships to TWSV, WSMoV, and MYSV are shown in three separate boxes. 
The descriptors for classifying tospovirus species were proposed in a tospovirus symposium in Taiwan in 1995 (20). These included distinct host reactions, $\mathrm{N}$ protein amino acid identity below $90 \%$, and a specific thrips specificity to separate distinct species. This species concept was well adapted at the tospovirus symposium in the Netherlands in 1998 (37). Because the $\mathrm{N}$ proteins of MYSV and PSMV share 99.6\% amino acid identity (Table 2) and have no apparent sequence distance (Fig. 3), it appears that there are currently 13 distinct species in the genus Tospovirus.

The serogroup concept was widely used as one important criterion in the classification and establishment of new tospoviruses. Because the $\mathrm{N}$ protein is the most abundant protein of tospoviruses, serological comparison based on the $\mathrm{N}$ protein provides a convenient tool for detection and classification of tospoviruses. This system worked well when the number of tospoviruses was few. However, the number of new tospoviruses increased dramatically in recent years, and the numerical classification of serogroups, such as serogroup I, II, III, and IV, become confusing and conflicting. For example, it is difficult to assign a new numerical serotype or serogroup when several distinct tospoviruses are described at the same time. In addition, $\mathrm{N}$ protein cross-reactions occur between different tospovirus species, such as between TSWV and GRSV in this study, and among TSWV, TCSV, and GRSV in previous reports $(1,10,11)$. The recently reported species CSNV was also found to have a slight serological cross-reaction with TSWV, TCSV, and GRSV (3). Thus, the original classification of TSWV as serogroup I and GRSV and TCSV as serogroup II $(10,11)$ is apparently not appropriate. It is

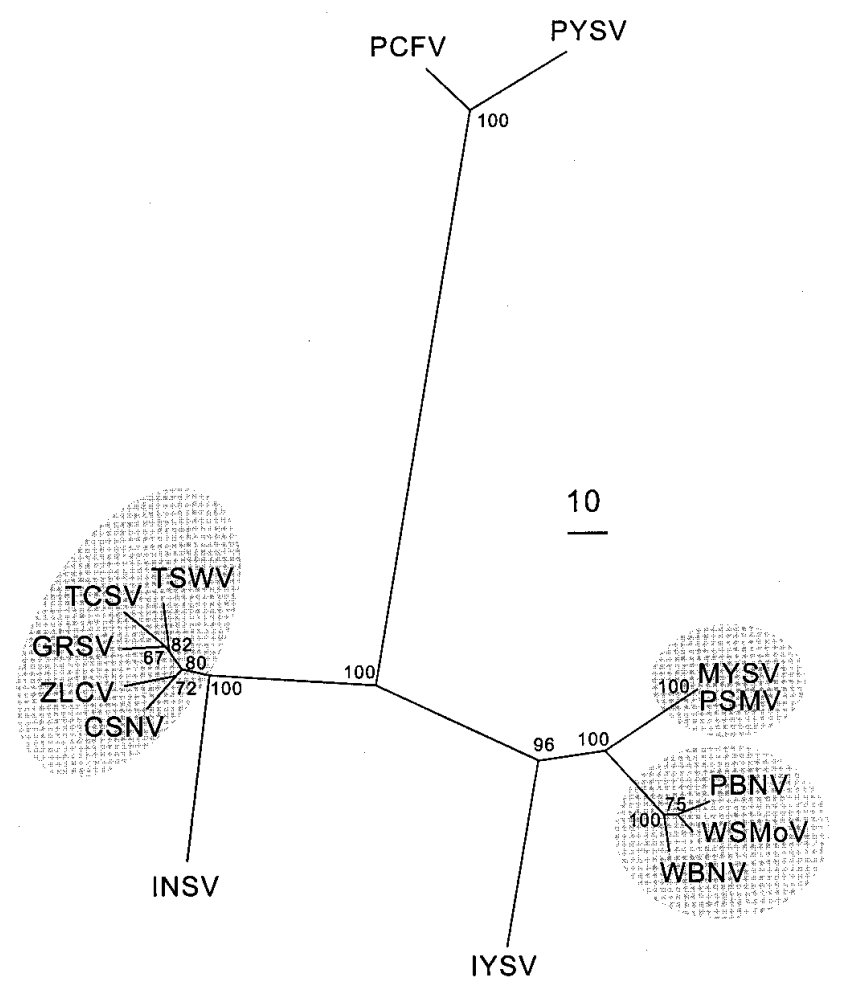

Fig. 3. Phylogenetic relationships of the nucleocapsid protein amino acid sequence of Peanut chlorotic fan-spot virus (PCFV) with those of other reported tospoviruses. The scale for genetic distances is indicated in the middle right quadrant. The viruses with potential serological relationships are shadowed in the same cluster. CSNV, Chrysanthemum stem necrosis virus; GRSV, Groundnut ringspot virus; INSV, Impatiens necrotic spot virus; IYSV, Iris yellow spot virus; MYSV, Melon yellow spot virus; PBNV, Peanut bud necrosis virus; PSMV, Physalis severe mottle virus; PYSV, Peanut yellow spot virus; TCSV, Tomato chlorotic spot virus; TSWV, Tomato spotted wilt virus; WBNV, Watermelon bud necrosis virus; WSMoV, Watemelon silver mottle virus; and ZLCV, Zucchini lethal chlorosis virus. expected that serological relationships of tospoviruses match well with the degrees of the $\mathrm{N}$ protein homology. Results of Table 1 and Figure 3 predict that serological relatedness should exist among TSWV, TCSV, GRSV, CSNV, and ZLCV. Therefore, we agree with the suggestion by Moyer (37) that the original numerical system should be abandoned and replaced with a type species in the group. Thus, all viruses serologically related to TSWV should be placed within the TSWV serogroup. Strong serological cross-reactions also occur among WSMoV, WBNV, and PBNV $(1,25,41)$. These three tospoviruses should be classified in the same serogroup as originally proposed, but the name of serogroup IV should be changed to the WSMoV serogroup. Thus, by combining the concept of species and the $\mathrm{N}$ protein serology, the current 13 tospoviruses can be classified as two major serogroups, the TSWV serogroup containing five species (TSWV, GRSV, TCSV, CSNV, and ZLCV) and the WSMoV serogroup containing three species (WSMoV, PBNV, and WBNV); plus five distinct monotypic serogroups with INSV, MYSV, IYSV, PYSV, and PCFV (Fig. 3).

Several tospoviruses have been reported to infect peanut and cause varying degrees of crop losses $(19,22,41,42,46)$. A ringspot disease of peanut is caused by GRSV occurring in South Africa, but GRSV is serologically distinct from PCFV as shown in this study. Bud necrosis disease of peanut in India is caused by PBNV, which belongs to the WSMoV serogroup (41). Although PCFV and PBNV share a common vector, $S$. dorsalis $(5,41)$, they are distinct viruses based upon serological properties. In India, PYSV causes localized chlorotic or necrotic lesions on peanut and other host plants and is not serologically related to TSWV (42). Although PCFV has a closer relationship with PYSV than the other tospoviruses compared, their $\mathrm{N}$ proteins share only $67.5 \%$ amino acid identity, indicating that they are two distinct tospovirus species.

The S RNA of PCFV is 2,833 nts in length, with two ORFs that are separated by an intergenic A-U rich region. The ambisense arrangement of the two PCFV ORFs is characteristic of the S RNA of tospoviruses. A terminal consensus nucleotide sequence of $8 \mathrm{nts}$ has been found in the viral RNAs of virus species within each genus of the family Bunyaviridae $(16,38)$. The last 8 nts $\left(5^{\prime}-\right.$

TABLE 2. Comparison of nucleotide identities (\% nt) and amino acid identities ( $\%$ aa) of the $5^{\prime}$-nontranslated region (5NTR), the NSs gene, the intergenic region (IG) and the $3^{\prime}$-nontranslated region (3NTR) of Peanut chlorotic fan-spot virus with those of other reported tospoviruses ${ }^{\mathrm{a}}$

\begin{tabular}{lccccc}
\hline & & \multicolumn{2}{c}{ NSs } & & \\
\cline { 3 - 4 } Viruse & 5NTR $(\% \mathrm{nt})$ & $\% \mathrm{nt}$ & $\%$ aa & IG (\% nt) & 3NTR (\% nt) \\
\hline TSWV & 44.8 & 39.9 & 27.3 & 50.5 & 49.4 \\
GRSV & 40.3 & 40.3 & 19.3 & 52.8 & 43.0 \\
TCSV & $\ldots$ & $\ldots$ & $\ldots$ & $\ldots$ & 45.6 \\
CSNV & $\ldots$ & $\ldots$ & $\ldots$ & $\ldots$ & 50.6 \\
ZLCV & $\ldots$ & $\ldots$ & $\ldots$ & $\ldots$ & 51.3 \\
INSV & $\ldots$ & 38.5 & 20.3 & 49.5 & 54.4 \\
WSMoV & 57.6 & 41.0 & 23.2 & 44.7 & 61.9 \\
WBNV & $\ldots$ & $\ldots$ & $\ldots$ & $\ldots$ & 55.4 \\
PBNV & 53.0 & 41.3 & 23.0 & 50.3 & 59.4 \\
PSMV & 49.3 & 39.9 & 54.2 & 50.0 & 49.3 \\
IYSV & 50.7 & 42.5 & 30.0 & 47.7 & 57.1 \\
PYSV & 66.7 & 60.1 & 21.9 & 48.7 & 75.0 \\
\hline
\end{tabular}

a Sequence comparisons were conducted with the GAP program of the Genetics Computer Group (GCG) package (version 9.0; Genetics Computer Group, Madison, WI). The GenBank codes of the nucleotide sequences are: TSWV, Tomato spotted wilt virus (D13926); GRSV, Groundnut ringspot virus (L12048); TCSV, Tomato chlorotic spot virus (S54325); CSNV, Chrysanthemum stem necrosis virus (AF067068); ZLCV, Zucchini lethal chlorosis virus (AF067069); INSV, Impatiens necrotic spot virus (X66972); WSMoV, Watemelon silver mottle virus (U78734); WBNV, Watermelon bud necrosis virus (U27809); PBNV, Peanut bud necrosis virus (U27809); PSMV, Physalis severe mottle virus (AF067151); IYSV, Iris yellow spot virus (AF001387); and PYSV, Peanut yellow spot virus (AF013994). 
AUUGCUCU- $3^{\prime}$ ) at the $3^{\prime}$-terminal end of the PCFV viral S RNA are identical to those of S RNAs of all reported tospoviruses, consistent with PCFV belonging to the genus Tospovirus in the family Bunyaviridae.

\section{ACKNOWLEDGMENTS}

This study was supported in part by the Council of Agriculture of the Republic of China on Taiwan (87AST-1.4-FAD-0.1[2-1]). We thank R. J. Chiu, H. T. Hsu, and R. J. M. Kormelink for editing the manuscript and providing advice.

\section{LITERATURE CITED}

1. Adam, B., Yeh, S. D., Reddy, D. V. R., and Green, S. K. 1993. Serological comparison of tospovirus isolates from Taiwan and India with impatiens necrotic spot virus and different tomato spotted wilt virus isolates. Arch. Virol. 130:237-250.

2. Bailey, J. M., and Davidson, N. 1976. Methylmercury as a reversible denaturing agent for agarose gel electrophoresis. Anal. Biochem. 70:75-85.

3. Bezerra, I. C., Resende, R. de O., Pozzer, L., Nagata, T., Kormelink, R., and De Ávila, A. C. 1999. Increase of tospoviral diversity in Brazil with the identification of two new tospovirus species, one from chrysanthemum and one from zucchini. Phytopathology 89:823-830.

4. Black, L. M., Brakke, M. K., and Vatter, A. E. 1963. Purification and electron microscopy of tomato spotted wilt virus. Virology 20:120-130.

5. Chen, C. C., and Chiu, R. J. 1996. A tospovirus infecting peanut in Taiwan. Acta Hortic. 431:57-67.

6. Chu, F.-H., and Yeh, S.-D. 1998. Comparison of ambisense M RNA of watermelon silver mottle virus with other tospoviruses. Phytopathology 88:351-358.

7. Cortês, I., Livieratos, I. C., Derks, A., Peters, D., and Kormelink, R. 1998. Molecular and serological characterization of iris yellow spot virus, a new and distinct tospovirus species. Phytopathology 88:12761282 .

8. Cortes, I., Pereira, A., Goldbach, R., Peters, D., and Kormelink, R. 1998. An RT-PCR procedure to amplify S RNA sequences of distinct tospoviruses. Pages 35-37 in: Proc. Int. Symp. Tospovirus Thrips Floral Veg. Crops, 4th., Wageningen, the Netherlands.

9. Dayhoff, M. O., Barker, W. C., and Hunt, L. T. 1983. Establishing homologies in protein sequences. Methods Enzymol. 91:524-525.

10. de Avila, A. C., de Haan, P., Kormelink, R., Resende, R. de O., Goldbach, R. W., and Peters, D. 1993. Classification of tospoviruses based on phylogeny of nucleoprotein gene sequences. J. Gen. Virol. 74:153-159.

11. de Avila, A. C., de Huguenot, C., Resende, R. de O., Kitajima, E. W., Goldbach, R. W., and Peters, D. 1990. Serological differentiation of 20 isolates of tomato spotted wilt virus. J. Gen. Virol. 71:2801-2807.

12. de Haan, P., de Avila, A. C., Kormelink, R., Westerbroek, A., Gielen, J. J. L., Peters, D., and Goldbach, R. 1992. The nucleotide sequence of the S RNA of impatiens necrotic spot virus, a novel tospovirus. FEBS Lett. 306:27-32

13. de Haan, P., Kormelink, R., Resende, R. de O., van Poelwijk, F., Peters, D., and Goldbach, R. 1991. Tomato spotted wilt virus L RNA encodes a putative RNA polymerase. J. Gen. Virol. 71:2207-2216.

14. de Haan, P., Wagemakers, L., Peters, D., and Goldbach, R. 1989. Molecular cloning and terminal sequence determination of the $\mathrm{S}$ and $\mathrm{M}$ RNAs of tomato spotted wilt virus. J. Gen. Virol. 70:3469-3473.

15. de Haan, P., Wagemakers, L., Peters, D., and Goldbach, R. 1990. The S RNA segment of tomato spotted wilt virus has an ambisense character. J. Gen. Virol. 71:1001-1007.

16. Elliott, R. M. 1990. Molecular biology of the Bunyaviridae. J. Gen. Virol. 71:501-522

17. Felsenstein, J. 1985. Confidence limits on phylogenies: An approach using the bootstrap. Evolution 39:783-791.

18. German, T. L., Ullman, D. E., and Moyer, J. W. 1992. Tospoviruses: Diagnosis, molecular biology, phylogeny, and vector relationships. Annu. Rev. Phytopathol. 30:315-348.

19. Ghanekar, A. M., Reddy, D. V. R., Iizuka, N., Amin, P. W., and Gibbons, R. W. 1979. Bud necrosis of groundnut (Arachis hypogaea) in India caused by tomato spotted wilt virus. Ann. Appl. Biol. 93:173-179.

20. Goldbach, R., and Kuo, G. 1996. Introduction: Proceedings of the international symposium on tospovirus and thrips of floral and vegetable crops. Acta Hortic. 431:21-26.

21. Gooderham, K. 1984. Transfer techniques in protein blotting. Pages 165178 in: Methods in Molecular Biology. Vol. 1. Proteins. J. M. Walker, ed. Humana Press, Clifton, NJ.

22. Halliwell, R. S., and Philley, G. 1974. Spotted wilt of peanut in Texas.
Plant Dis. Rep. 58:23-25.

23. Holmes, D. S., and Quigley, M. 1981. A rapid boiling method for the preparation of bacterial plasmids. Anal. Biochem. 114:193-197.

24. Ie, T. S. 1970. Tomato spotted wilt virus. No. 39 in: Descriptions of Plant Viruses. Commonw. Mycol. Inst./Assoc. Appl. Biol., Kew, England.

25. Jain, R. K., Pappu, H. R., Pappu, S. S., Krishna Reddy, M., and Vani, A. 1998. Watermelon bud necrosis tospovirus is a distinct virus species belonging to serogroup IV. Arch. Virol. 143:1637-1644.

26. Kato, K., Hanada, K., and Kameya-Iwaki, M. 2000. Melon yellow spot virus: A distinct species of the genus Tospovirus isolated from melon. Phytopathology 90:422-426.

27. Kormelink, R., de Haan, P., Meurs, C., Peters, D., and Goldbach, R. 1992. The nucleotide sequence of the M RNA segment of tomato spotted wilt virus, a bunyavirus with two ambisense RNA segments. J. Gen. Virol. 73:2795-2804.

28. Kormelink, R., Kitajima, B. W., de Haan, P., Zuidema, D., Peters, D., and Goldbach, R. 1991. The nonstructural protein (NSs) encoded by the ambisense S RNA segment of tomato spotted wilt virus is associated with fibrous structures in infected plant cells. Virology 181:459-468.

29. Kormelink, R., Storms, M., Lent, J. V., Peters, D., and Goldbach, R. 1994. Expression and subcellular location of the NSm protein of tomato spotted wilt virus (TSWV), a putative viral movement protein. Virology 200:56-65.

30. Law, M. D., and Moyer, J. W. 1990. A tomato spotted wilt-like virus with a serologically distinct N protein. J. Gen. Virol. 71:933-938.

31. Law, M. D., and Moyer, J. W. 1991. Nucleotide sequence of the 3' noncoding region and $\mathrm{N}$ gene of the $\mathrm{S}$ RNA of a serologically distinct tospovirus. J. Gen. Virol. 72:2597-2601.

32. Law, M. D., and Moyer, J. W. 1992. The nucleotide sequence and genomic organization of the impatiens necrotic spot tospovirus M RNA. Virology 188:732-741.

33. Maiss, B., Ivanova, L., Breyd, E., and Adam, G. 1991. Cloning and sequencing of the S RNA from a Bulgarian isolate of tomato spotted wilt virus. J. Gen. Virol. 72:461-464.

34. Maniatis, T., Fritsch, B. F., and Sambrook, J. 1982. Molecular Cloning: A Laboratory Manual. Cold Spring Harbor Laboratory, Cold Spring Harbor, NY.

35. Milne, R. G. 1970. An electron microscope study of tomato spotted wilt virus in sections of infected cells and in negative stain preparations. J. Gen. Virol. 6:267-276.

36. Mohamed, N. A., Randles, J. W., and Francki, R. I. B. 1973. Protein composition of tomato spotted wilt virus. Virology 56:12-21.

37. Moyer, J. W. 1999. Tospoviruses (Bunyaviridae). Pages 1803-1807 in: Encyclopedia of Virology. A. Granoff and R. G. Webster, eds. Academic Press, New York.

38. Murphy, F. A., Fauquet, C. M., Bishop, D. H. L., Ghabrial, S. A., Jarvis, A. W., Martelli, O. P., Mayo, M. A., and Summers, M. D., eds. 1995. Virus taxonomy: Classification and nomenclature of viruses. Sixth report of the international committee on taxonomy of viruses. Arch. Virol. 10(Suppl.):300-315.

39. Pang, S. Z., Slightom, J. L., and Gonsalves, D. 1993. The biological properties of a distinct tospovirus and sequence analysis of its S RNA. Phytopathology 83:728-733.

40. Purcifull, D. E., and Batchelor, D. L. 1977. Immunodiffusion tests with sodium dodecyl sulfate (SDS)-treated plant viruses and plant viral inclusions. Fla. Agric. Exp. Stn. Bull. 788.

41. Reddy, D. V. R., Ratna, A. S., Sudarshana, M. R., and Kiran Kumar, I. 1992. Serological relationships and purification of bud necrosis virus, a tospovirus occurring in peanut (Archis hypogaea L.) in India. Ann. Appl. Biol. 120:279-286.

42. Reddy, D. V. R., Sudarshana, M. R., Ratna, A. S., Reddy, A. S., Amin, P. W., Kumar, I. K., and Murthy, A. K. 1990. The occurrence of yellow spot virus, a member of tomato spotted wilt virus group, on peanut (Arachis hypogaea L.) in India. Pages 77-88 in: Virus-thrips-plant interactions of tomato spotted wilt virus. H. T. Hsu and R. H. Lawson, eds. U.S. Dep. Agric. Agric. Res. Ser. Bull. 87.

43. Sanger, F., Nicklen, S., and Coulson, A. R. 1977. DNA sequencing with chain-terminating inhibitors. Proc. Natl. Acad. Sci. USA 83:571-579.

44. Satyanarayana, T., Gowda, S., Lakshminarayana Reddy, K., Mitcell, S. E., Dawson, W. O., and Reddy, D. V. R. 1998. Peanut yellow spot virus is a member of a new serogroup of Tospovirus genus based on small (S) RNA sequence and organization. Arch. Virol. 143:353-364.

45. Satyanaryana, T., Mitchell, S. B., Reddy, D. V. R., Brown, S., Kresovich, S., Jarret, R., Naidu, R. A., and Demski, J. W. 1996. Peanut bud necrosis tospovirus S RNA: Complete nucleotide sequence, genome organization and homology to other tospoviruses. Arch. Virol. 141:85-98.

46. Sreenivasulu, P., Demski, J. W., Reddy, D. V. R., Naidu, R. A., and Ratna, A. S. 1991. Purification and some serological relationships of tomato spotted wilt virus isolates occurring on peanut (Arachis hypogaea) in the USA. Plant Pathol. 40:503-507. 
47. Tas, P. W. L., Boerjan, M. L., and Peters, D. 1977. The structural proteins of tomato spotted wilt virus. J. Gen. Virol. 36:267-279.

48. van den Hurk, J., Tas, P. W. L., and Peters, D. 1977. The ribonucleic acid of tomato spotted wilt virus. J. Gen. Virol. 36:81-91.

49. van Kammen, A., Henstra, S., and Le, T. S. 1966. Morphology of tomato spotted wilt virus. Virology 30:574-577.

50. Wang, M., and Gonsalves, D. 1990. ELISA detection of various tomato spotted wilt virus isolates using specific antisera to structural proteins of the virus. Plant Dis. 74:154-158

51. Yeh, S.-D., and Chang, T.-F. 1995. Nucleotide sequence of the $\mathrm{N}$ gene of watermelon silver mottle virus, a proposed new member of the genus Tospovirus. Phytopathology 85:58-64.
52. Yeh, S. D., Chao, C. H., Cheng, Y. H., and Chen, C. C. 1996. Serological comparison of four distinct tospoviruses by polyclonal antibodies to purified nucleocapsid proteins. Acta Hortic. 431:122-134.

53. Yeh, S.-D., and Gonsalves, D. 1984. Purification and immunological analyses of cylindrical-inclusion protein induced by papaya ringspot virus and watermelon mosaic virus 1. Phytopathology 74:1273-1278.

54. Yeh, S.-D., Lin, Y.-C., Cheng, Y.-H., Jih, C.-L., Chen, M.-J., and Chen, C.-C. 1992. Identification of tomato spotted wilt-like virus infecting watermelon in Taiwan. Plant Dis. 76:835-840.

55. Yeh, S. D., Sun, I. J., Ho, H. M., and Chang, T. F. 1996. Molecular cloning and nucleotide sequence analysis of the S RNA of watermelon silver mottle virus. Acta Hortic. 31:244-260. 